\title{
Incidence of obesity, adiposity and physical activity pattern as risk factor in adults of Delhi, India
}

\author{
Kshetrimayum Surmala Devi, Nilupher, Urvashi Gupta, Meenal Dhall*, Satwanti Kapoor \\ Department of Anthropology, University of Delhi, Delhi, 110007, India
}

\section{A R T I C L E I N F O}

\section{Keywords:}

Obesity

Adiposity

Physical activity

Delhi

\begin{abstract}
A B S T R A C T
Objective: This study investigates the patterns of physical activity, associations between physical activity and the prevalence of obesity (defined by BMI), adiposity markers and physiological markers.

Methods: The sample included 418 adults of both gender in the age group of 20-55 years.

Design: Cross-sectional study and sample included adult volunteers of both gender. Participants underwent anthropometric measurements, blood pressure measurement and assessment of physical activity. Physical activity level was assessed using the Global Physical Activity Questionnaire (GPAQ).

Result: Total physical activity measured in mean MET minutes/week was 400.3 for males and 265.3 for females. Males (34.2\%) had slightly greater level of moderate physical activity as compared to females (30.3\%). Over all, the ORs of lower physical activity were higher in females of all the anthropometric indices. Odds of physical activity in overweight participant among males were 1.21 while in females it was 1.696. The odds of lower physical activity showed association with CI (males, OR-1.118; females, OR-2.781, WC (males, OR-1.026; females, OR-1.194), BMI (males, OR- 1.211; females, OR-1696) and blood pressure (SBP- males, OR- 1.105; females, OR-1.237; DBP- males; OR-1.174, females; OR-1.355). No significant association was found between physical activity and AVI.

Conclusion: Majority of adults were physically inactive. BMI, WC and CI were all significant predictors of physical inactivity. Physical inactivity was associated with obesity and blood pressure.
\end{abstract}

\section{Introduction}

Physical activity is a primary means of development and maintenance of individual and population health and well-being. ${ }^{1}$ It is defined as "any force exerted by skeletal muscles that Results in energy expenditure above resting level". ${ }^{2}$ The international recommendations by the World Health Organization (WHO) for PA for persons $<65$ years are 150 min moderate or 75 min vigorous activity per week ${ }^{3}$ and includes work-related activity, leisure time activity, but also sporadic and bouted PA, exercise training, and sports.

Numerous studies have demonstrated that physical activity could substantially decrease mortality. PA can reduce the risk for overweight, obesity, cardiovascular diseases (CVD), diabetes type II, ${ }^{4}$ depression ${ }^{5}$ and fractures. ${ }^{6}$ Studies suggested that sedentary living is associated with higher all-cause mortality ${ }^{7}$ and it is accountable for about onethird of deaths due to CHD and type 2 diabetes. Regular physical activity and exercise reduced plays a fundamental role in the prevention and management of coronary heart disease, obesity, type 2 diabetes, and other chronic diseases and conditions. ${ }^{8}$ On the other hand, physical inactivity has become a major risk factor for chronic non-communicable diseases in populations Studies have demonstrated that physical inactivity contributes to nearly $15-20 \%$ of the overall risk for coronary heart disease, type 2 diabetes, colon cancer, breast cancer, musculoskeletal diseases and psychological disorders. ${ }^{9,10}$

Obesity is now a major global burden in public health including cardiovascular disease, dyslipidemia, hypertension, type 2 diabetes, some forms of cancer, ${ }^{11}$ and is associated with a wide range of complications affecting many different aspects of physiology. ${ }^{12}$ Lack of physical activity is one of the main risk factors that lead to overweight and obesity and its associated health complications. The prevalence of physical inactivity and obesity is on a rapid increase and as a consequence has resulted in major public health problems worldwide. ${ }^{13}$ The fundamental cause of obesity is excessive consumption of high calorie foods with less physical activity level i.e. when the energy intake is in excess of expenditure (https://www.sciencedirect.com/science/ article/pii/S1550413116305964. ${ }^{14}$

Overweight and obesity is often assessed according to body mass index (BMI). However, in terms of disease risks, BMI has been criticized

\footnotetext{
* Corresponding author. Department of Anthropology, University of Delhi, 110007, Delhi, India.

E-mail address: say2meenal@gmail.com (M. Dhall).
} 
as not being an optimal measure of overweight and obesity. ${ }^{15}$ Adiposity measure viz. waist circumference (WC), ${ }^{16}$ waist-to- hip ratio (WHR) ${ }^{17}$ and waist-to-height ratio (WHtR) are considered as better predictors of obesity-related morbidity and mortality risk disease than other anthropometric measurements. However, most of the previous studies on the associations between physical activity and adiposity markers primarily used BMI,WHR, WHtR but did not include new adiposity measures viz. conicity index (CI), abdominal volume index (AVI). Hence, the present study aims to study the patterns of physical activity, associations between physical activity and the prevalence of obesity (defined by BMI), adiposity markers and physiological markers.

\section{Materials and methods}

\subsection{Study population}

The present study is a cross-sectional study conducted among Delhi population. A total of 418 adults of both gender of age group 20-55 years were recruited for the study. Data was collected from May 2015 to December 2017. Before taking the detail information and measurements, ethical permission was taken and informed consent was obtained from each participant.

\subsection{Anthropometric measures}

Anthropometric measurements such as stature, body weight, minimum waist circumference and maximum hip circumference were taken using standardized techniques. Blood pressure was measured in a sitting position by sphygmomanometer in millimeters of mercury. JNC VII, 2004 classification was followed for blood pressure. Waist circumference was obtained as the minimum circumference of the waist between the lower rib and iliac crest at the minimal level and the values were classified following WHO guidelines The body mass index (BMI) was calculated using the formula weight $(\mathrm{kg}) / \mathrm{height}^{2}\left(\mathrm{~m}^{2}\right)$. The studied participants were classified on the basis of BMI following WHO International Standard and recommended cut-off points for Asians. The waist-to-hip ratio (WHR) was calculated by dividing the waist circumference $(\mathrm{cm})$ by the hip circumference $(\mathrm{cm})$. WHR was calculated as WC divided by hip circumference. Participants were categorized on the basis of the World Health Organization's cut-offs. Recommended standard cutoffs were used for all the parameters. Abdominal volume index (AVI) is another anthropometric tool for estimating overall abdominal volume and calculated using waist circumference and hip. It reflects close relationship with the impairment of glucose metabolism. ${ }^{18} \mathrm{AVI}$ is calculated as:

Abdominal Volume Index (AVI)

$=\frac{\left[2 \times(\text { waist })^{2}(\mathrm{~cm})+0.7 \mathrm{~cm}(\text { waist-hip })^{2}(\mathrm{~cm})\right]}{[1000]}$

\subsection{Physical activity measures}

The level of physical activity was assessed using the Global Physical Activity Questionnaire (GPAQ) which has been developed by the World Health Organization. GPAQ is comprised of 16 questions that assess physical activity in three different domains i.e. at work, in transport, and discretionary. For each domain and intensity of physical activity, the MET-minutes per week were computed following the existing guidelines. For the determining the overall energy expenditure using GPAQ data, 4 METs are assigned to the time spent in moderate activities, and 8 METs to the time spent in vigorous activities. For the calculation of a categorical indicator, the total time spent in physical activity during a typical week, the number of days as well as the intensity of the physical activity was taken into account. The categorical score classifies individuals into low, moderate, and high, and the criteria for these levels were: (i) High: 7 or more days of any combination of walking, moderate-intensity or vigorous-intensity activities achieving a minimum total PA of at least 3000 MET-min/week. (ii) Moderate: 5 or more days of moderate-intensity activity and/or walking, moderate-, or vigorous-intensity activities achieving a minimum of at least 600 MET minutes/week and a maximum of 2999 MET minutes/week (iii) Low: a person not meeting any of the above mentioned criteria. ${ }^{1}$

\subsection{Statistical analysis}

Data were analyzed using the Statistical Packages for Social Sciences (SPSS) version 16.0. Results are presented as of mean, standard deviation and quartile range. For data comparison, chi-square test for categorical variables and student t-test for continuous variables were used. Multinomial logistic regression model were used to assess the risk factors of the variables. Quartile of abdominal volume index (AVI) and conicity index was created and accordingly categorized them into four groups for further analysis: second and third quartiles were set as reference.

\section{Results}

The mean and standard deviation for anthropometric and adiposity indices by gender are given in Table 1 . The mean age of male participants was $37.5( \pm 12.17)$ years while that of females was 40.32 ( \pm 11.66$)$ years. Mean height and weight was found to be significantly higher in males. Males had a significantly higher mean value of minimum waist circumference $(\mathrm{p}<0.001)$, waist hip ratio $(\mathrm{p}<0.5)$ and abdominal volume index $(\mathrm{p}<0.001)$ than females. Mean values of maximum hip circumference, body mass index and conicity index were found to be significantly higher in females. Both the mean systolic and diastolic BP was found to higher in men. All the sex differences were found to be statistically significant at $\mathrm{p}<0.001$.

Distribution of physical activity level and mean of MET-min/week is shown in Table 2. Total physical activity measured in mean MET minutes/week was 400.3 for males and 265.3 for females. Findings indicated a relatively low physical activity level. Out of 418

Table 1

Biological characteristics of the study participants.

\begin{tabular}{|c|c|c|c|}
\hline Variables & Males & Females & $t$-test \\
\hline Age (years) & $37.58 \pm 12.17$ & $40.32 \pm 11.66$ & $-2.791^{* *}$ \\
\hline Minimum waist circumference $(\mathrm{cm})$ & $90.86 \pm 12.60$ & $84.48 \pm 11.77$ & $6.499 * * *$ \\
\hline Maximum hip circumference $(\mathrm{cm})$ & $96.87 \pm 8.88$ & $101.44 \pm 10.73$ & $-5.578^{* * *}$ \\
\hline BMI $\left(\mathrm{kg} / \mathrm{m}^{2}\right)$ & $26.29 \pm 4.78$ & $28.01 \pm 5.54$ & $-4.022 * * *$ \\
\hline WHR & $0.93 \pm 0.99$ & $0.86 \pm 0.51$ & $2.150^{*}$ \\
\hline Systolic Blood Pressure BP (mmHg) & $131.17 \pm 17.31$ & $123.52 \pm 17.22$ & $5.362^{* * *}$ \\
\hline Diastolic Blood Pressure BP (mmHg) & $87.15 \pm 11.69$ & $80.77 \pm 11.60$ & $6.632^{* * *}$ \\
\hline AVI (Abdominal Volume Index) $\left(\mathrm{cm}^{2}\right)$ & $16.92 \pm 5.23$ & $14.83 \pm 3.86$ & $5.818^{* * *}$ \\
\hline Conicity Index (CI) $\left(\mathrm{m}^{2 / 3} / \mathrm{kg}^{1 / 2}\right)$ & $1.17 \pm 0.09$ & $1.25 \pm 0.12$ & $8.158^{* * *}$ \\
\hline
\end{tabular}


Table 2

Distribution of physical activity level and mean of MET-min/week.

\begin{tabular}{|c|c|c|c|}
\hline Variables & Males & Females & Total \\
\hline Physical activity (mins/week) & 400.3 & 265.3 & \\
\hline Moderate physical activity & $63(34.2 \%)$ & $71(30.3 \%)$ & $134(32.1 \%)$ \\
\hline Low physical activity & $121(65.8 \%)$ & $163(69.7 \%)$ & $284(67.9 \%)$ \\
\hline Total & $184(100)$ & $234(100)$ & $418(100)$ \\
\hline
\end{tabular}

populations, $32.1 \%$ of them were found to have moderate physical activity and $67.9 \%$ had low physical activity. However, males (32.2\%) had slightly higher level of moderate physical activity as compared to females (30.3\%).

The prevalence of obesity according to level of physical activity is shown in Table 3. In both males $(20.1 \%)$ and females $(22.6 \%)$, the proportion of overweight was lowest in the moderately active group. Also, both in males (41.3\%) and females (49.6\%), a higher proportion of the overweight individual was found in the least physically active group as compared to the moderately active group.

Table 4 shows the distributions of total physical activity level in quartiles of AVI. AVI was classified into quartiles: quartiles 1(25th P), quartiles $2\left(50^{\text {th }} \mathrm{P}\right)$, quartiles $3(75$ th $\mathrm{P})$ and quartile 4 (85th P). In both males and females, a more or less equal distribution was seen. Prevalence of low physical activity in Q1, Q2, Q3 and Q4 were $14.7 \%$, $16.8 \%, 17.4$ and $16.8 \%$ in males while it was $17.5 \%, 17.1 \%, 17.5 \%$ and $17.5 \%$ in females respectively.

Table 5 shows the distributions of total physical activity with the quartiles of conicity index. CI was classified into quartiles: quartiles 1 (25th P), quartiles $2\left(50^{\text {th }} \mathrm{P}\right)$, quartiles $3(75$ th $\mathrm{P})$ and quartile 4 (85th P). In females, participants representing the 1st quartile of CI were characterized by lower low physical activity and it decreases with increasing CI quartiles. In case of males, low physical activity was found to be highest in the 4th quartiles of $\mathrm{CI}$ and it increases with increasing CI quartiles.

Multinomial regression models of physical activity on related independent variables are shown in Table 6 . The Results indicate that waist circumference (OR, 1.194), WHR (OR, 1.097), CI (OR, 1.253) were all associated with increased odds of being physically 'inactive' in females. In females, the odds of lower physical activity was found to be 1.6 in overweight category as compared to individuals with normal weight category while it was 1.2 times in case of males. Females in the 1st quartile of AVI had the highest odds of being physically 'inactive' (OR, 1.059) as compared to lowest quartile. Males and females in the 4th quartiles of CI had 1.1 and 2.7 fold increased odds of being physically inactive. The odds of lower physical activity also showed strong association with systolic and diastolic blood pressure in females as compared to males (OR, 1.237; 95\% CI, 0.708,2.162, OR, 1.355; 95\% CI, 0.725, 2.535).

\section{Discussion}

In many countries, physical inactivity levels are rising with major implications for the prevalence of non-communicable diseases (NCD) and the general health of populations worldwide. ${ }^{19}$ Physical inactivity increases the risk of developing abdominal adiposity, diabetes and cardiovascular disease. ${ }^{20}$ In addition, physical inactivity accounts for an estimated 3.2 million annual deaths (6\% of global deaths), considering the fourth leading risk factor for global mortality. ${ }^{21}$

In the present study, males tended to have significantly higher mean of minimum waist circumference $(\mathrm{p}<0.001)$, waist hip ratio ( $\mathrm{p}<0.5)$, abdominal volume index $(\mathrm{p}<0.001)$ and blood pressure than females. Whiles females had significantly higher mean values of maximum hip circumference and body mass index. Study by Dua et al. (2014) observed a mean BMI of 27.7 in females and 25.8 in males. In the present study, mean CI was found to be significantly higher in females ( $p<0.001$ ) which is consistent with most of the published literature. $^{22}$ Conicity index which accounts for WC, weight and height quantify the excess abdominal fat, the increase in values agrees with fat deposition in the central region of the body and has a theoretical range of $1.0<\mathrm{CI}<1.73 .^{23}$

The prevalence of moderate physical activity was only $32.2 \%$ in males while $30.3 \%$ in females. About $69.7 \%$ of the women in the study had inadequate level of physical activity. This adds to the evidence of increasing sedentary lifestyle among the women in India. Recent studies have documented a much higher levels of physical inactivity in India ranging from 38 to $70 \% .{ }^{24}$ This is consistent with other studies where females had significantly higher levels of light physical activity than males. $^{25}$

A recent study was conducted on four regions of India by the Indian Council of Medical Research- India Diabetes (ICMR- INDIAB) study, utilizing the GPAQ. Nearly half of the population in the four regions studied was reported of being inactive. This translates to 392 million inactive individuals in India and males were significantly more active than females. ${ }^{24}$

The present study documented that higher proportion of the overweight individual was found in the low physical activity group as compared to the moderately active group. The finding indicated that physical inactivity is associated with obesity. This could be attributed to rapid urbanization, characterized by, irregular food habits, consumption of energy-dense food, sedentary lifestyles, lack of physical active together with reduced energy expenditure, have exacerbated the incidence of obesity and non communicable diseases. Bailey et al. ${ }^{26}$ have reported that lower physical activity levels are associated with an increased probability of being overweight/obese. Studies by Mungreiphy et al. ${ }^{27}$ also documented a higher general obesity in North Indian population (Delhi). Other studies have reported a higher prevalence of obesity in adult females $(18 \%)$ as compared with males $(14.5 \%)$ in a cross-sectional study in Delhi. ${ }^{28}$

Several studies have emphasized the relationship between BMI and physical activity. In the present study, the significance of recently described body indices, CI and AVI in assessment of incidence of physical activity level were also evaluated. Differences in physical activity profiles of participants were observed according to lower and upper quartiles of CI. In females, higher proportion of the least physically active group was found to be highest in the 1st quartile of CI and it decreased with increasing CI quartiles. In case of males, low physical activity was found to be highest in the 4th quartiles of CI and it increased with increasing CI quartiles.

Overweight participants had 1.6 and 1.2 times higher odds of physical inactivity compared with individuals in normal group in both males and females. The odds of lower physical activity showed

Table 3

The prevalence of obesity according to level of physical activity.

\begin{tabular}{|c|c|c|c|c|c|c|c|c|}
\hline \multirow[t]{2}{*}{$B M I$} & \multicolumn{4}{|l|}{ Males N (\%) } & \multicolumn{4}{|l|}{ Females N (\%) } \\
\hline & Underweight & Normal & Overweight & Total & Underweight & Normal & Overweight & Total \\
\hline Moderate physical activity & $3(1.6)$ & $23(12.5)$ & $37(20.1)$ & $63(34.2)$ & $4(1.7)$ & $14(6)$ & $53(22.6)$ & $71(30.3)$ \\
\hline Low physical activity & $6(3.3)$ & $39(21.2)$ & $76(41.3)$ & $121(65.8)$ & $3(1.3)$ & $44(18.8)$ & $116(49.6)$ & $163(69.7)$ \\
\hline Total & $9(4.9)$ & $62(33.7)$ & $113(61.4)$ & $184(100)$ & $7(3)$ & $58(24.8)$ & $169(72.2)$ & $234(100)$ \\
\hline
\end{tabular}


Table 4

Distributions of total physical activity level in quartiles of AVI.

\begin{tabular}{|c|c|c|c|c|c|c|c|c|c|c|}
\hline \multirow[t]{2}{*}{ AVI quartiles } & \multicolumn{5}{|c|}{ Males N (\%) } & \multicolumn{5}{|c|}{ Females N (\%) } \\
\hline & Q1 & Q2 & Q3 & Q4 & Total & Q1 & Q2 & Q3 & Q4 & Total \\
\hline Moderate physical activity & $19(10.3)$ & $15(8.2)$ & $14(7.6)$ & $15(8.2)$ & $63(34.2)$ & $17(7.3)$ & $19(8.1)$ & $18(7.7)$ & $17(7.3)$ & $71(30.3)$ \\
\hline Low physical activity & $27(14.7)$ & $31(16.8)$ & $32(17.4)$ & $31(16.8)$ & $121(65.8)$ & $41(17.5)$ & $40(17.1)$ & $41(17.5)$ & $41(17.5)$ & 163(69.7) \\
\hline Total & $46(25)$ & $46(25)$ & $46(25)$ & $46(25)$ & $184(100)$ & $58(24.8)$ & $59(25.2)$ & $59(25.2)$ & $58(24.8)$ & $234(100)$ \\
\hline
\end{tabular}

Table 5

Distributions of total physical activity level in quartiles of CI.

\begin{tabular}{|c|c|c|c|c|c|c|c|c|c|c|}
\hline \multirow[t]{2}{*}{ Conicity Index quartiles } & \multicolumn{5}{|c|}{ Males N (\%) } & \multicolumn{5}{|c|}{ Females N (\%) } \\
\hline & Q1 & Q2 & Q3 & Q4 & Total & Q1 & Q2 & Q3 & Q4 & Total \\
\hline Moderate physical activity & $9(4.9)$ & $10(5.4)$ & $19(10.3)$ & $25(13.6)$ & $63(34.2)$ & $26(11.1)$ & $22(9.4)$ & $17(7.3)$ & $6(2.6)$ & $71(30.3)$ \\
\hline Low physical activity & $13(7.1)$ & $16(8.7)$ & $43(23.4)$ & $43(23.4)$ & $121(65.8)$ & $57(24.4)$ & $47(20.1)$ & $38(16.2)$ & $21(9.0)$ & $163(69.7)$ \\
\hline Total & $22(12)$ & $26(14.1)$ & $62(33.7)$ & $74(40.2)$ & $184(100)$ & $83(35.5)$ & $68(29.5)$ & $55(23.5)$ & $27(11.5)$ & $234(100)$ \\
\hline
\end{tabular}

Table 6

Multinomial regression models of physical activity on related independent variables.

\begin{tabular}{|c|c|c|c|c|c|}
\hline \multirow[t]{2}{*}{ Variables } & \multirow[t]{2}{*}{ Categories } & \multicolumn{2}{|l|}{ Male } & \multicolumn{2}{|l|}{ Female } \\
\hline & & $\operatorname{Exp}(\mathrm{B})$ & CI $(95 \%)$ & $\operatorname{Exp}(B)$ & CI $(95 \%)$ \\
\hline \multirow[t]{2}{*}{ Body Mass Index (BMI) } & Overweight & 1.211 & {$[0.634,2.316]$} & 1.696 & {$[0.352,1.380]$} \\
\hline & Normal & $0^{\mathrm{a}}$ & & & \\
\hline \multirow[t]{2}{*}{ Waist Circumference (WC) } & Risk & 1.026 & {$[0.556,1.895]$} & 1.194 & {$[0.662,2.151]$} \\
\hline & Normal & $0^{\mathrm{a}}$ & & & \\
\hline \multirow[t]{2}{*}{ Waist Hip Ratio (WHR) } & Risk & 0.838 & {$[0.448,1.569]$} & 1.097 & {$[0.610,1.971]$} \\
\hline & Normal & $0^{\mathrm{a}}$ & & & \\
\hline \multirow[t]{3}{*}{ Conicity Index (CI) } & $1^{\text {st }}$ quartile & 0.842 & {$[0.466,1.522]$} & 0.854 & {$[0.504,1.448]$} \\
\hline & $4^{\text {th }}$ quartile & 1.118 & {$[0.548,1.889]$} & 2.781 & {$[0.328,23.612]$} \\
\hline & $2^{\text {nd }}$ and 3rd quartile & $0^{\mathrm{a}}$ & & & \\
\hline \multirow[t]{3}{*}{ Abdominal Volume Index } & $1^{\text {st }}$ quartile & 0.622 & {$[0.263,1.469]$} & 1.059 & {$[0.480,2.337]$} \\
\hline & $4^{\text {th }}$ quartile & 0.904 & {$[0.263,1.469]$} & 0.988 & {$[0.501,1.948]$} \\
\hline & $2^{\text {nd }}$ and 3rd quartile & $0^{\mathrm{a}}$ & & & \\
\hline \multirow[t]{2}{*}{ Systolic Blood Pressure } & Hypertensive & 1.105 & {$[0.566,2.156]$} & 1.237 & {$[0.708,2.162]$} \\
\hline & Normal & $0^{\mathrm{a}}$ & & & \\
\hline \multirow[t]{2}{*}{ Diastolic Blood Pressure } & Hypertensive & 1.174 & {$[0.598,2.304]$} & 1.355 & {$[0.725,2.535]$} \\
\hline & Normal & $0^{\mathrm{a}}$ & & & \\
\hline
\end{tabular}

$\mathrm{CI}=$ Confidence Interval.

$0^{\mathrm{a}}=$ Reference (normal).

Dependent category = BMI, WC, WHR, CI, AVI, SBP and DBP.

Reference category $=$ Moderate physical activity.

association with CI and blood pressure in females. A study conducted by Aljadhey, concluded that the risk of hypertension was higher in physically inactive individuals than in those who were physically active (Odds ratio, 1.1; 95\% Confidence interval, 1.07 to 1.12 , $\mathrm{p}<0.0001$ ). ${ }^{29}$

\section{Conclusion}

The present study highlighted that the level of physical activity was very low in the majority of the population, when assessed with multidomain of GPAQ. Males were found to be more active than females. Higher proportion of the overweight individual was found in the physically low active group as compared to the moderately active group. Marked differences in physical activity level of participants were observed at the lower and upper quartiles of $\mathrm{CI}$ in both males and females. Overweight and hypertensive participants had higher odds of physical inactivity compared with individuals in normal group.

\section{Acknowledgements}

The authors are thankful to the participants of the study for their immense help and support. They are also grateful to the Department of
Anthropology and R\&D, University of Delhi for infrastructure and DSTSERB (Grant number: SB/YS/LS-60/2014) \& DU-DST PURSE grant for financial assistance.

\section{Appendix A. Supplementary data}

Supplementary data to this article can be found online at https:// doi.org/10.1016/j.cegh.2019.03.008.

\section{References}

1. World Health Organization. WHO STEPS Surveillance Manual: The WHO STEPwise Approach to Chronic Disease Risk Factor Surveillance. Geneva, Switzerland: World Health Organization; 2005.

2. Caspersen CJ, Powell KE, Christenson GM. Physical activity, exercise, and physical fitness: definitions and distinctions for health-related research. Publ Health Rep. 1985;100(2):126.

3. WHO. Physical Activity and Adults - Recommended Levels of Physical Activity for Adults Aged 18-64 Years. 2016; 2016.

4. Kriska AM, Saremi A, Hanson RL, et al. Physical activity, obesity, and the incidence of type 2 diabetes in a high-risk population. Am J Epidemiol. 2003;158:669-675.

5. Strawbridge WJ, Deleger S, Roberts RE, Kaplan GA. Physical activity reduces the risk of subsequent depression for older adults. Am J Epidemiol. 2002;156:328-334.

6. Stattin K, Michaelsson SC, Larsson A, Wolk L. BybergLeisure-time physical activity and risk of fracture: a cohort study of 66,940 men and women. J Bone Miner Res. 2017 
Aug;32(8):1599-1606

7. Ekelund U, Ward HA, Norat T, et al. Physical activity and all-cause mortality across levels of overall and abdominal adiposity in European men and women: the European Prospective Investigation into Cancer and Nutrition Study (EPIC). Am J Clin Nutr. 2015;101:613-621.

8. Berry JD, Pandey A, Gao A, Leonard D, Farzaneh-Far R, Ayers C, et al. Physical fitness and risk for heart failure and coronary artery disease. Circ. Heart Fail. 2013;6(4):627-634.

9. Bauman A, Miller Y. The public health potential of health enhancing physical activity. In: Oja P, Borms J, eds. Health-enhancing Physical Activity. International Council of Sport Science and Physical Education; 2004.

10. Dhall M, Kapoor AP, Bhasin P, Kapoor. Satwanti. Patterns of physical activities influencing cardio vascular and respiratory functions. Int J Med Health Sci. April. 2018;-7:Issue-2.

11. Fruh SM. Obesity: risk factors, complications, and strategies for sustainable longterm weight management. Journal of the American Association of Nurse Practitioners 2017;29 S3-S14.

12. Martin-Rodriguez E, Guillen-Grima F, Marti A, Brugos-Larumbe A. Comorbidity as sociated with obesity in a large population: the APNA study. Obes Res Clin Pract 2015;9(5):435-447.

13. Brundtland GH. From the World Health Organization. Reducing risks to health, promoting healthy life. J Am Med Assoc. 2002;288:1974.

14. Ekkekakis P, Vazou S, Bixby WR, Georgiadis E. The mysterious case of the public health guideline that is (almost) entirely ignored: call for a research agenda on the causes of the extreme avoidance of physical activity in obesity. Obes Rev. 2016;17:313-329 (2) (PDF) Do Dopaminergic Impairments Underlie Physical Inactivity in People with Obesity?

15. Lee IM, Shiroma EJ, Lobelo F, Puska P, Blair SN, Katzmarzyk PT. Eff ect of physical inactivity on major non communicable diseases worldwide: an analysis of burden of disease and life expectancy. Lancet. 2012;380:219-229.

16. Czernichow S, Kengne AP, Stamatakis E, Hamer M, Batty GD. Body mass index, waist circumference and waist-hip ratio: which is the better discriminator of cardiovascular disease mortality risk?: evidence from an individual-participant meta-analysis of 82864 participants from nine cohort studies. Obes Rev. 2011;12(9):680-687.

17. Petursson H, Sigurdsson JA, Bengtsson C, Nilsen TI, Getz L. Body configuration as a predictor of mortality: comparison of five anthropometric measures in a 12 year follow-up of the Norwegian HUNT 2 study. PLoS One. 2011;6(10):e26621.

18. Guerrero-Romero F, Rodríguez-Morán M. Abdominal volume index. An anthropometry-based index for estimation of obesity is strongly related to impaired glucose tolerance and type 2 diabetes mellitus. Arch Med Res. 2003;34:428-432.

19. World Health Organization. Global Recommendations on Physical Activity for Health. Geneva: WHO; 2010.

20. Qin L, Corpeleijn E, Jiang C, Thomas GN, Schooling CM, Zhang W, Cheng KK, Leung GM, Stolk RP, Lam TH. Physical activity, adiposity, and diabetes risk in middle-aged and older Chinese population: the Guangzhou Biobank Cohort Study. Diabetes Care. 2010;33(11):2342-2348.

21. World Health Organization. Global Health Risks: Mortality and Burden of Disease Attributable to Selected Major Risks. Geneva: World Health Organization; 2009.

22. Shenoy U, Jagadamba. Influence of central obesity assessed by conicity index on lung age in young adults. J Clin Diagn Res. 2017 Apr;-11(4):CC09-CC12.

23. Andrade MD, Freitas MC, Sakumoto AM, Pappiani C, Andrade SC, Vieira VL, et al. Association of the conicity index with diabetes and hypertension in Brazilian women. Arch Endocrinol Metab. 2016;60(5):436-442.

24. Anjana RM, Pradeepa R, Das AK, Deepa M, Bhansali A, Joshi SR, et al. Physical activity and inactivity patterns in India - Results from the ICMRINDIAB study (Phase1) [ICMR-INDIAB-5]. Int J Behav Nutr Phys Act. 2014;11(1):26.

25. Tripathy JP, Thakur JS, Jeet G, Chawla S, Jain S, Prasad R. Urban rural differences in diet, physical activity and obesity in India: are we witnessing the great Indian equalisation? Results from a cross-sectional STEPS survey. BMC Public Health. 2016;16:816.

26. Bailey DM, Davies B, Young IS, Jackson MJ, Davison GW, Isaacson R, et al. EPR spectroscopic detection of free radical outflow from an isolated muscle bed in exercising humans. J Appl Physiol. 2003;94:1714-1718.

27. Mungreiphy NK, Dhall M, Tyagi R, Saluja K, Kumar A, Tungdim MG, et al. Ethnicity, obesity and health pattern among Indian population. J Nat Sci Biol Med. 2012;3:52-59.

28. Dua S, Bhuker M, Sharma P, Dhall M, Kapoor S. Body MassIndex relates to blood pressure among adults. N Am J Med Sci. 2014 Feb;6(2):89-95.

29. Aljadhey $\mathrm{H}$. Physical inactivity as a predictor of high prevalence of hypertension and health expenditures in the United States: a cross-sectional study. Tropical Journal of Pharmaceutical Research December. 2012;11(6):983-990. 